\title{
Synthesis, citotoxicity activity of new Cyclozonarone angular isomer
}

\author{
Cuellar, M; ${ }^{\text {a }}$ Quiñones, N; ${ }^{a}$ Villena, J; ${ }^{\text {a }}$ Salas, C.; ${ }^{b}$ Espinoza, L.' \\ ${ }^{a}$ Facultad de Farmacia, Universidad de Valparaíso, Av. Gran Bretaña 1093, Valparaíso Chile. \\ ${ }^{b}$ Departamento de Química Orgánica, Pontificia Universidad Católica de Chile, Vicuña Mackenna 4860, \\ Santiago, Chile. Departamento de Química, \\ 'Universidad Técnica Federico Santa María, Av. España N¹680, Valparaíso, Chile. \\ *mauricio.cuellar@uv.cl
}

Keywords: ent-cyclozonarone; angular isomer; antitumoral activity

\section{INTRODUCTION}

Among the great variety of natural products, found in plants, algae and sea sponge, we can find compounds that have a quinonic/hydroquinonic moiety united to a terpenic skeleton. Natural (-)cyclozonarone (1), is a drimanic benzoquinone derivative isolated from algae Dintyopteris undulata that posseses a powerful feeding-deterrant activity towards young abalones ${ }^{1}$ furthermore shows anticancer activity. ${ }^{2}$ The absolute configuration of $\mathbf{1}$ was establish through a six-step route, starting from natural (-) polygodial, leading us to the synthetic enantiomer (+)-cyclozonarone (2), that showed antileshmania activity. ${ }^{3}$ Later, (-)-cyclozonarone was synthesized starting from (+)-albicanol. ${ }^{4}$ Both routes of synthesis were based on the Diels-Alder reaction.
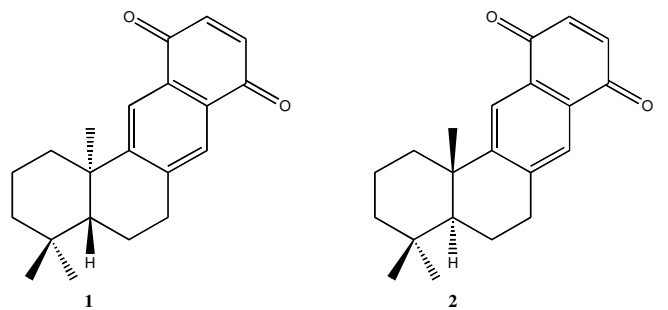

\section{RESULTS AND DISCUSSION}

In this work, we described to the synthesis of an angular isomer of (+)-ciclozonarona. The compound 6 was synthesized using as synthetic strategy the Diels-Alder cycloaddition reaction between diene $\mathbf{5}$ and p-benzoquinone, in a sequence of six steps from confertifoline 3 (Scheme 1). Furthermore we reported herein the in vitro testing of 2 and 6 to include normal and tumor cell lines in order to determine the broadness of the activity. The antitumoral activities of compounds were assayed against two cells lines (DU-145 and PC-3) (Table 1).
Scheme 1. Reagents and conditions. (a) Ref 5; (b) vinylmagnesium bromide, THF; (c) $\mathrm{SOCl}_{2}$; (d) pbenzoquinone, $\mathrm{Bz}$, reflux.

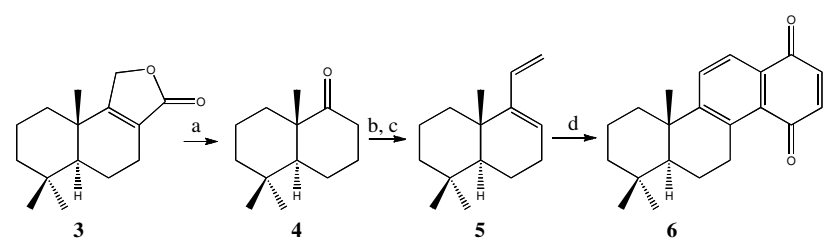

Table 1. Antitumoral activity, $\mathrm{IC}_{50}(\mu \mathrm{M})$

\begin{tabular}{|c|c|c|c|}
\hline Compound & DU-145 & PC-3 & DHF \\
\hline $\mathbf{2}$ & 20 & 25 & 37 \\
6 & 42 & 45 & 65 \\
\hline
\end{tabular}

\section{CONCLUSION}

In summary, we described here the synthesis of a new cyclozonarene isomer and anticancer evaluation of ent-cyclozonarone and its angular isomer. As compared with the tumor cell lines analyzed, we found ent-cyclozonarone had major antitumoral effect (Table 1). The comparison of the respective IC50 showed that normal cells were less sensitive to 2 and 6 compounds.

\section{ACKNOWLEDGEMENTS}

The authors thank Facultad de Farmacia de la Universidad de Valparaíso and CORFO Grant 07 CT9PDT-68

\section{REFERENCES}

${ }^{1}$ Kurata, K., Tanaguchi, K., Susuki, M.; Phytochem., 1996, 41, 749.

${ }^{2}$ Curtis, M. D.; Shiu, K.; Butler, W. M. e Huffmann, J. C. J. Am. Chem. Soc. 1986, 108, 3335

${ }^{3}$ Cortés, M., Valderrama, J. A. Cuellar, M. Armstrong, V., Preite, M.; J. Nat. Prod., 2001, 64, 348.

${ }^{4}$ Seifert, K., Schröder, J., Matthes, B. Tetrahedron Lett., 2001, 42, 8151.

${ }^{5}$ Benites, J., Preite, M., Cortés, M.; Synth. Commun. 2001, 31 (9), 13471354. 